\title{
Nursing education and complexity pedagogy: Faculty experiences with an e-learning platform
}

\author{
Gail Joyce Mitchell ${ }^{* 1}$, Beryl Pilkington ${ }^{1}$, Christine M. Jonas-Simpson ${ }^{1,2}$, Isolde Daiski ${ }^{1}$, Nadine L. Cross ${ }^{2}$, Nancy \\ Johnston ${ }^{1}$, Caroline P. O'Grady ${ }^{1}$, Eva H. Peisachovich ${ }^{1}$, Sannie Y. Tang ${ }^{1}$ \\ ${ }^{1}$ Faculty of health, School of Nursing, York University, Toronto, Canada \\ ${ }^{2}$ York-University Health Network Academy, Toronto, Canada
}

Received: November 8, 2015

DOI: $10.5430 /$ jnep.v6n5p60
Accepted: January 6, 2016

Online Published: January 10, 2016

\begin{abstract}
Objective: Nine nursing faculty explored the effectiveness of teaching undergraduate and graduate nursing courses using a complexity-based pedagogy with an e-learning platform. Complexity pedagogy requires a commitment by educators to reside within a networked community of teachers-learners where all participants contribute to an organically growing curriculum over the course of study.

Methods: The approach is non-linear and student-centered. Faculty co-developed course outlines, resources for teaching learning, and regularly connected over a two-year time frame to mentor each other, strategize, and share resources. Individual faculty first wrote about their experiences of e-learning with complexity pedagogy and then collaborated to generate this descriptive report. Results: Faculty reported enhanced student-student engagement and higher quality critical thinking than experienced previously with traditional e-learning platforms.

Conclusions: This article suggests complexity pedagogy offers quality education and merits further exploration.
\end{abstract}

Key Words: Complexity pedagogy, e-Learning, Education, Nursing, Innovation

\section{COMPleXity INNOVAtion FOR E- gogy and to offer insights about possibilities for meaningful LEARNING change in nursing education.}

As a group of nurse educators we collaborated in order to describe and discern insights about our shared experiences of using complexity pedagogy ${ }^{[1]}$ with an e-learning platform. Our teaching with complexity pedagogy happened in undergraduate and graduate nursing courses, and in project work with health professionals over a two-year period. All nine of us used an e-learning platform called Daagu that was developed by educators at York University, Canada in order to support faculty who wanted a non-linear, networked platform for engaged teaching-learning activities. The purpose of this paper is to describe our experiences with complexity peda-

\subsection{Education and calls for change}

Reports of quality in higher education linked with specific pedagogies is not well established. ${ }^{[2]}$ One possible exception to the absence of research on outcomes is the body of work on e-learning and constructivism. ${ }^{[3,4]}$ There is however, a gap in knowledge regarding other specific pedagogies, such as complexity, and as noted by Wilson-Doenges \& Gurung, ${ }^{[2]}$ research is needed in order to better understand what learning and teaching actually benefit students. Our work connects with and advances the call to develop an episte-

*Correspondence: Gail Joyce Mitchell; Email: gailm@yorku.ca; Address: Faculty of health, School of Nursing, York University, Toronto, Canada. 
mology of learning. . heavily influenced by the importance of difference. ${ }^{[5]}$ Complexity pedagogy leverages individual differences and diversities in order to promote emergence of new/different thinking and learning. Difference in the complexity-based platform is not a difference that categorizes and judges, rather, difference is the foundation of living and learning systems. We are all different-experiences, intentions, and perspectives-and our differences can generate insight and understanding when coupled with the intention to listen, connect, and discern. ${ }^{[1]}$

Calls for change in nursing educational approaches have been reported since the late 1980s. Authors such as Bevis \& Watson, ${ }^{[6]}$ Dieklemann, ${ }^{[7-10]}$ Diekelmann \& Schekel, ${ }^{[11]}$ Giddens $\&$ Brady, ${ }^{[12]}$ Giddens et al.,${ }^{[13]}$ Ironside, ${ }^{[14]}$ and Johnston ${ }^{[15]}$ lament that the content driven, didactic approaches leave little room for critical reflection, engagement with diverse ideas, and creative thinking. Over the past decade calls for change intensified with appeals for creative, collaborative, and open systems that are more inclusive, nimble, meaningful, and exciting. ${ }^{[16]}$ The role of educators is changing and access to technology invites educators, especially in higher education, to reject thinking of knowledge as content to be delivered to students who have not been involved in defining and selecting the curriculum of study. Contemporary theorists conceptualize knowledge, not as content, but as process and preparation for collaborative possibilities, creativity, and shared actions across disciplinary and geographical borders. ${ }^{[1,16]}$ Also, scholars are expanding understandings of what it means to not only be present with each other through reading and writing words, ideas, and feelings, but also how writing or expressing self in an online environment can help persons find unexpected answers and possibilities. ${ }^{[15,17]}$

\subsection{Literature review}

There is evidence supporting the effectiveness of, and satisfaction with, web-based learning. ${ }^{[18-23]}$ Boling, Hough, Krinsky, Saleem, and Stevens ${ }^{[24]}$ affirmed that students preferred courses that are more interactive and that include multimedia for teaching-learning. But as noted by others, enhanced technology without a change in pedagogy does not alter students' experiences. ${ }^{[25]}$ Price and Kirkwood ${ }^{[25]}$ contend there is limited evidence to demonstrate that educators have changed their teaching practices with the introduction of technology, and if they have, it is not known how those changes influence the teaching-learning experience. Educators indicate that technology that helps meet students' needs is more compelling for change, but that insufficient time and limited resources make changes in actual teaching practices unlikely. ${ }^{[26]}$ Further, many educators have not had opportunity to study and incorporate principles from the emergent pedagogies (e.g., constructivism, connectivism, and complexity) that require student engagement and teacher facilitation in imaginative and co-emergent inquiry. ${ }^{[24,27]}$

\subsection{Complexity pedagogy}

Complexity thinking has been informing educators for more than a decade. There are numerous complexity scholars and educational theorists who have influenced our thinking and teaching. ${ }^{[1,28-40]}$ Complexity thinking fosters provocative and divergent thinking, deep understanding, and innovative insights that co-emerge in community discussions. ${ }^{[35-37]}$ Difference is valued and leveraged in complexity arenas such that questions and different understandings come forth in unexpected ways. Complexity teaching requires an active, learner-centered approach where students and teachers influence each other's emerging understandings. ${ }^{[27,40]}$

There are numerous resources for pursuing a deeper understanding of how complexity thinking can inform education. ${ }^{[28,40]}$ Fundamental principles from these complexity theorists/educators that influenced our actions as educators include the following:

- Complex systems are emergent, dynamic and selfcreating/organizing

- Complex systems cannot be controlled or managed by outsiders

- Complex systems change in non-linear ways that involve feedback loops and unexpected shifts in direction

- Humans are complex systems that relate with multiple other complex systems in dynamic and ever-changing ways

- Knowledge and understanding are personal, historical, embodied, and dynamic according to the intentions, desires, and goals of the persons involved

- Teaching-learning is a process in which all members of a networked community contribute

Guided by these principles educators from Fine Arts, Digital Imaging, Education, Psychology and Nursing embarked on a three-year process to create a complexity-inspired e-learning platform called Daagu.

\section{DESCRIPTION OF TEACHING-LEARNING WITH COMPLEXITY PEDAGOGY}

\subsection{The e-learning platform}

Daagu is a web-based platform that supports transdisciplinary discussions and teaching-learning by encouraging the sharing of different perspectives and experiences. The platform facilitates students to direct and create their own learning pathways; increases student engagement; cap- 
tures crucial moments of insight; identifies areas of interest and disinterest; and provides teachers and students with a visual map of the activity within a set of discussions and/or across disciplines. There is no menu or blueprint for enacting complexity pedagogy, as one would expect with a non-linear and emergent frame of thinking. We did however develop guidelines to help shape the way we might connect with students and that informed our complexity pedagogy.

\subsection{Guiding complexity pedagogy}

The nine educators involved in this project began by establishing the liberating-constraints ${ }^{[30]}$ for the courses being taught. Liberating-constraints are the big ideas or perspectives of the course or subject of study that establish boundaries for student choices of pathways and connections for learning. The liberating-constraints help students to align or situate their contributions to the curriculum. An example of liberatingconstraints for a course on Global Health, for example, might be creating the following four perspectives to guide discussions and curriculum growth: health and poverty, health and politics, health and social justice, and health and gender.

Complexity thinking leverages different views and a diversity of experiences in order to challenge assumptions and provoke discussion of issues important to the course of study and student interests. The idea of leveraging and highlighting difference-different experiences, perspectives, possibilities, thinking-is particularly appealing as a source for the coemergence of novel ideas and new understandings. ${ }^{[27,33]}$ In order to deepen our understanding and practice as educators, we developed the following guidelines based on complexity scholars. ${ }^{[27-40]}$

- Establish the liberating-constraints-the big ideas that contain course-relevant perspectives and ideas.

- Craft critical questions that require various views and conceptual approaches-stretching the realm of possibility for student engagement with diverging ideas.

- Establish essential understandings to invite a deeper level of thinking and exploration of conceptual relationships.

- Encourage reflection and recursion of ideas to foster the learner's ability to organize, combine, and formulate additional questions.

- Acknowledge co-emergent learning for learner awareness and growth.

- Encourage learners to recognize and reflect on their aha moments as expressions of learning.

- Request that students express their emotions relating to learning within community using emotive icons.

- Invite students to contribute resources and discussions to curriculum.
- Recognize and identify patterns of thinking across groups of students, domains, or spans of time so as to provoke learners' insights/thinking.

- Provoke, perturb and challenge ideas in order to expose unstated assumptions.

- Help students make connections to neighboring ideas and/or contexts by modeling this process in the teachers' own posts.

- Help students to make explicit the application of ideas/concepts to their embodied practices and day-today life activities.

- Invite diverse perspectives, Does anyone think about this differently? Or can anyone add another view here?

- Encourage rigor of thinking through meaningful conversation that is open and emergent with others.

Complexity pedagogy can be enacted in any delivery modeface to face, blended, or fully online. However, our experience has been that e-learning technology can facilitate or hinder complexity pedagogy as a way of engaging and relating with students. The Daagu platform, although still being evaluated, revised, and developed, holds promise for complexity-based education.

\subsection{Participants}

We are faculty colleagues teaching in undergraduate and graduate nursing programs. The $\mathrm{MScN}$ program includes core courses: a six-credit theoretical/philosophical foundations of nursing, three research courses (a total of nine course credits), and a three-credit advanced nursing practicum. Students can complete a thesis option in addition to required electives. In the undergraduate program, some electives (a course on aging, and one on women's health), are offered in blended and on-line formats. We collaborated on this project because we shared the concern that students lacked opportunities to engage and collaborate in a networked learning community committed to conversing about different ideas that challenge the assumptions of everyday practices and collectively generate possibilities for moving forward. We were dissatisfied with the notion of one teacher with authority who selects content, sequences that content in modules or books, and then dispenses content in predefined ways that do not typically involve student choice or contribution. We were also dissatisfied when students expected to give content back to teachers, in the teacher's preferred ways, without bringing their own voices and views into the thinking arena. In many of our experiences of teaching online, students analyze and synthesize ideas from the literature with a flare of habit that does not often get below the surface of restating others' ideas. Students have not typically been invited into spaces where collective inquiry of difference generates insight and new 
learning. We want to support a more critical, thoughtful, and meaningful way of engaging students that changes the role of educator from truth dispenser to truth questioner in a distributed field of teaching-learning where all participants contribute to the curriculum in an organic and dynamic way. We believe that complexity thinking provides direction for creating this kind of educational space. ${ }^{[41]}$

Specific courses being taught by authors include: a foundations theory and philosophy course in the $\mathrm{MScN}$ program, and graduate electives on suffering, grieving, and education. Graduate courses are capped at 15 students. Three undergraduate courses with 40 students, one on Women's Health and two on Aging have been taught in the fully on-line platform. GM was the project lead for developing Daagu and NC was on the original team of educators informing the complexity pedagogy. GM also worked with ST and NC on a research project evaluating the effectiveness of an educational intervention for enhancing the compassion and critical consciousness for health care professionals. Other faculty, FBP, CJ-S, and ID have experience with complexity pedagogy and e-learning technology, while the rest (EP, NJ, CO) had experience with technology-enhanced education but were novices with complexity pedagogy. Even though we were all open to the basic ideas and approaches to teaching-learning with complexity, some of us still experienced anxiety and discomfort with letting go of the more traditional contentdriven and linear teaching methods that had directed our own educational and teaching experiences.

For the report described here each of us addressed in a journalistic style several questions beginning with our overall experience of the complexity pedagogy and the Daagu platform, our likes and dislikes, the quality of the engagement we experienced with students, and how we might improve the platform. The lead author first compiled views of the group into one document and then all participated in revisions and clarifications. The following compilation represents our collective experiences.

\section{EXPERIENCES WITH COMPLEXITY E- LEARNING USING THE DAAGU PLATFORM}

At this early point, our overall experience with complexity pedagogy and the e-learning platform Daagu is mostly favourable. We see a different kind of student engagement and participation that is, we believe, of a higher quality than what we have witnessed in our prior courses using other Learning Management Systems (LMS) such as Moodle and WebCT. Several notable benefits are elaborated in order to consider the implications for our work as nursing educators.

The first thing we noticed was that because students had the Published by Sciedu Press ability to initiate discussion forums based on their own curiosities and beliefs, within the boundaries of the perspectives and essential understandings (liberating-constraints) of the course, they were highly engaged with ideas and each other. The freedom to choose the context for their own learning facilitated student involvement in expected and unexpected ways. For instance, we expected that students would add to the curriculum by initiating discussions and uploading resources, but we found the amount of student-to-student conversing and exploring somewhat surprising. In one course, Theoretical and Philosophical Foundations of Nursing Science, students contributed almost half of the curriculum resources (scholarly articles, TedTalks, YouTubes, artforms, etc) generated in one 12-week term. In two undergraduate courses, after the first three weeks, students regularly contributed curricular content in order to meet learning outcomes with the teacher facilitating, questioning, perturbing, and highlighting connections among ideas.

As educators, we found that teaching with complexity thinking was liberating and challenging-at the same time. Letting go of the more familiar teacher-driven style in order to invite students to lead their own learning process was unfamiliar; especially, since there was a good deal of uncertainty that we would meet pre-defined learning outcomes. The uncertainty highlighted our need to trust that students, when supported as a community of teachers-learners, would not only learn, they would exceed learning expectations. Our role as educators shifted from expounding on what we thought about the topics under discussion to posing questions and encouraging students to ask their own questions and to share resources they found meaningful in their process of inquiry. While it was a leap of faith that this would work, it was gratifying to witness the multiple unfolding conversations and the diversity of perspectives being shared. It became evident that students are very adept at exploring questions and issues that are meaningful to them. Our challenge was to recognize opportune moments to interject questions or comments creating perturbations and inviting alternative views and the closer scrutiny of assumptions. We developed a different kind of expertise with a much longer "shelf life": that of learning how to teach and learn in a networked community.

Complexity pedagogy also enabled us to make connections and interconnections with groups of students. Student expressions emerged from a variety of contexts including nursing, psychological, spiritual, cultural and critical as they considered intersecting ideas across different experiences. As ideas were transferred across context and domain there were also opportunities to see and appreciate a whole picture and a larger reality. This level gazing may be linked with Romesin, and Verden-Zöller's, ${ }^{[42]}$ insights that there are 
both local, linear connections and holistic sensibilities in human discernment-both are required for understanding. Complexity pedagogy as a methodology for engagement enables possibilities for creating a culture of teaching and learning that promotes dialogue while expanding inclusiveness and diversity. Complexity offers one possibility for more collaborative, participatory, and transformative learning practices within the context of higher education.

Several of us had previously been influenced by scholars like Dewey ${ }^{[43]}$ and Freire ${ }^{[44-46]}$ so it was not a big stretch to think about pedagogy from a complexity thinking stance. The "teacher as midwife"[45] metaphor has affinity with some fundaments of complexity-such as going with the students' ways and choices and seeing the processes involved within a much larger context of interconnections. The ideas of nonlinear learning, openness, reflection, critical thinking, and empowerment resonated among early educational activist thinking and complexity pedagogy. Several of us have also been influenced by the phenomenological and hermeneutic traditions in philosophy and nursing. We shared the belief that learning is not predominantly about exchanging content and synthesizing information. Complexity pedagogy supports learning as a dynamic, generative process that builds on the learning and insights co-emerging in a community of networked learners. ${ }^{[27]}$

Yet, some of our emerging experiences of teaching/learning with Daagu also prompted us to challenge a seemingly hidden and underdeveloped aspect of complexity pedagogy, the reality that students and teachers are political subjects embedded in political structures who do not share equal power and interests in constructing "liberating knowledge" $"[45,46]$ about the world, with an intent to reflect on/act upon/transform it. In the aforementioned research study that engaged a group of health care providers (HCP) in on-line discussion around compassionate practice and social justice, the authors in that study noticed that while HCP-participants readily took up everyday practice issues such as patient discharge and time constraints in the online discussions, other issues that are equally relevant to providing compassionate care to a diverse population, such as addressing racism and social injustice, were left relatively "silent" and un-explored. This observation has highlighted for us some important but under-examined issues in relation to a learner-directed educational approaches such as complexity pedagogy. We question, how could complexity pedagogy take into account the social positions of the learners, including how their race/class/gender positions may limit their learning possibilities and pedagogical interests? In the above study, some of us pondered if the relatively privileged positions of most of the HCP-participants in terms of their White, English-speaking, middle class backgrounds may have largely protected them from being the subjects of racism, classism, and other forms of discrimination, and thereby limited their awareness of and interests in exploring critical issues that may seem to have little relevance to their lives. We remain open to better understanding our role as critically thinking educators within a complexity pedagogy. Our experience of likes and dislikes further clarify.

\section{EXPERIENCES WITH COMPLEXITY AND THE E-LEARNING PLATFORM}

We conversed about what we liked and did not like about complexity pedagogy in the Daagu platform. Likes revolved around: seeing co-emergent curriculum that grew over the course term situated on student interests, high engagement, deep reflection and critical inquiry; the unburdening that accompanied the move away from having to be the expert authority; the freedom for students to start where they wanted with ideas and with questions that were the most interesting, perplexing, thought-provoking and/or affirming; and the non-linear patterns of collaboration, growth, and learning. We propose that complexity pedagogy helped students to make more meaningful connections to practice situations and enabled them to see the big picture with all the layers of issues and complex subtleties of real life. Students explored and appreciated the extreme unpredictability and nonlinearity in pathways to recovery for persons diagnosed with mental health issues, for instance, and also the complex and interconnected patterns of human relating in families and communities. We liked that the learning expressed by students was deep, original, and authentic in nature and that it often penetrated below the surface of ideas to question unexamined assumptions. Students freely contributed different perspectives, and explored the implications of holding different positions.

One example of this deep and more critical learning was students' explorations of the questions: What is truth? and, What is knowledge? This led to discussions of evidencebased practice (EBP), which has become a widely accepted expectation of professional practice in nursing — so much so that students were initially shocked to realize that this is a controversial topic. Upon exploring, they discovered that what counts as evidence has been debated over time, and that there are vigorous critiques of the EBP movement in the literature. As they sorted through the arguments for and against EBP, students shared how it has been taken up in their practice settings with little, if any, critique, and how they incorporate it in their own practice with little question of fit or effectiveness. From our previous experiences, discussions demonstrated a depth and sophistication of critical reflection and thinking that surpassed discussions in previous sections 
of this course. Addressing the quality of engagement, one teacher stated: "The quality of the learning expressed by students on Daagu was high. The majority of students expressed that they were very engaged using this platform". Overall, the level of interactivity we witnessed with a complexity approach is enhanced compared with other pedagogical approaches.

Our dislikes, or perhaps better stated as challenges, related to both the Daagu platform and complexity pedagogy. As anticipated with the new technology there were glitches that took some attention and time to resolve. The lack of structure for some students was threatening and they required more guidance and direction during uncertain times. In addition, it takes time to read and respond to student contributionsalthough not necessarily more effort compared to other elearning platforms. Another challenge we discussed linked with our own uncertainties of moving to a new way of teaching. It felt like being pushed and pulled outside of our comfort zones of familiarity and tradition. We were anxious about performing our educator responsibilities and about meeting our own expectations for quality education. One of us submitted, "There are some particular challenges with the open-endedness of Daagu in my experience-times when students feel overwhelmed with the options and possibilities that can be pursued and with the lack of time constraints, like a week for each discussion."

We also compared our own experiences of teaching with various e-learning platforms over the past decade. As a group we are very familiar with WebCT, Moodle, and the incorporation of other technologies to aid learning. We noted that while students can certainly have discussions and share resources in Moodle, it is a platform that encourages teacher-directed progression, with the teacher organizing and presenting content either chunked in modules or in weekly "sections". The linear format of Moodle creates isolated silos of ideas and discussions with limited opportunities for students to drive the process of inquiry based on their own questions and the directions these queries lead them. By comparison, the use of complexity pedagogy is relatively unbounded, with students being encouraged to pursue their own lines of inquiry related to some core questions and course concepts. Students are free to choose the discussions in which to participate, and to add new discussions as interests emerge. Although this freedom is frightening for some, the majority embraced the freedom of learning in community.

An organic curriculum in Daagu opens up during the course of study-like choreography it moves as the partners shift and attend to various ideas and questions. Teachers typically begin two or three discussions with critical questions and

Published by Sciedu Press rich-media resources to launch the course, and students tend to begin contributing resources and discussion threads within the first few weeks. The platform itself is visually appealing and the ability to create a discussion thread using an image provides the user the opportunity to identify the discussion in a visual way. The function of the growing thread of discussion facilitates engaging with the collective. Given that the Daagu platform provides users with the ability to access any thread at any time, rather than within a delineated time or discussion frame, reinforces the notion of complexity and enhances the interactivity among the learners.

In summary, compared to other LMS, we think that Daagu was more aesthetically pleasing and more expressive of complexity thinking with its design for meaningful engagement, self-organization, and organic growth. The nonhierarchical nature of curricular growth also demonstrates student-centeredness; once students figured out there was no one authority figure related to their learning or thinking, and no predefined path for achieving learning outcomes, most embraced the complexity platform. Students bounced ideas off each other and provided links to content that went far beyond what one teacher might have imagined or selected. Like other LMSs, evaluation of student performance still happens, but it shifts to how much students express deep exploration and understanding, rather than regurgitating a "one right way" of interpretation and answering. Complexity thinking and the Daagu platform better supports, we believe, students' critical thinking and questioning-which better promotes their becoming reflective practitioners.

\subsection{Improving complexity-based e-learning}

With respect to ways to improve the experience of teaching complexity-based pedagogy, we are considering several elements linked with the Daagu technology and developing one's way with complexity pedagogy. Regarding the technology, group mentoring for teachers and verbal, visual, and written orientation guides for students help. However, Daagu is an intuitive platform that does not present major hurdles for students or teachers. Still, having a responsive technical team to address issues or glitches is needed with any e-learning platform.

The development team is currently working on phase two of Daagu which will bring a new level of interactivity across disciplines and conceptual borders, and that will also improve basic functions for visualizing data, networks, student discussion views, emotional intelligence, and contributions to the curriculum. Several other features need to be addressed, such as more robust administrator functionality for teachers to be able to create groups and accept assignments in the platform. Spaces for personal journaling for students and 
teachers and enhanced connectivity among learners and their ideas would be helpful additions. We have different views about how many characters to permit for student and teacher posts-some want a limit of 1,000 characters-which forces brevity-others want 5,000 for more depth and storytelling.

While students are reporting favourable experiences with the complexity pedagogy in the Daagu platform, as one educator stated, "I do not need Daagu to teach in this way." Educators can transform their pedagogy and engagement patterns with students in any format. If, however, educators want an e-learning platform that supports a complexity-inspired pedagogy, Daagu may be helpful. We have student comments and quotes to support that their learning is more meaningful, deep, and engaged than experiences with other online platforms. Daagu may not be appealing for students who want to be specifically directed in their learning. Students' experiences will be described in another publication due to the focus and length of this paper.

Regarding the pedagogy, there are limited resources about e-learning approaches with complexity pedagogy. Our group found that a mentoring process among faculty is helpful. The first courses were taught by three of us (GM, FBP, ID) who shared experiences and course materials-in order to be supportive and to learn in community. It is also helpful for faculty to shift their expectations about how the course might unfold. As there are typically only a few required readings to begin, students are encouraged to explore within the liberating constraints, to move from where they are to where they want to go in light of learning outcomes. Faculty are building banks of resources for various courses that will be available to students and teachers who want to question, perturb, consider, and provoke different views. Resources include case studies, videos, literature, and art forms to both animate discussion and enable a wide range of emerging themes to be pursued in more depth.

We do have some unanswered questions and perturbations that invite additional conversation. For instance, complexity has been questioned for its lack of apriori ethical guidelines and for its moral puzzlements. ${ }^{[35]}$ Certainly values and ethical relating are priority foci for a nursing program committed to relationships, inclusiveness, and social justice. We do not embrace the idea of apriori ethical standards but we also know that in professional nursing some ways of thinking and acting are more desirable than others. We do want to instill certain values and ways of relating that are critical, compassionate, and collaborative. How do we engage in the very real issues of social justice including the discomforts of having one's privileges challenged? How do we address the resistances to critical thinking on race, class, and gender differences? And how, in an e-learning platform, are issues of power and race, class, and gender differences brought to light? Complexity pedagogy creates inclusive spaces for conversing with the belief that difference and diversity are generative, necessary, and valued. We propose that thoughtful reflections and dialogues actually help students to make better ethical decisions because as understanding expands about issues of power, discrimination, and exclusion, mindful deliberations and discernments surface in conversations.

Osberg ${ }^{[39]}$ reminds us that our work as educators is to invite and inspire students to change in particular ways. Complexity thinking does not, we believe, change this intention. Woermann and Cilliers ${ }^{[47]}$ help us to see that: "ethics should be understood as something that constitutes both our knowledge and us, rather than as a normative system that dictates action" (p. 448). This inherent presence means, according to these authors, that we must hold a critical and open attitude toward the limits of knowledge. Ethics is always present in our ways of thinking and acting, and we bear the burden of the uncertainty that we cannot know ahead of time how to act-we can only live the commitment to an ethical conscience and to the awareness of how choices happen in the here and now and we can never know all the complexities of the situations we encounter. Further, ethics are always present in our represented forms of knowledge, our theories and how they come to be constructed, by whom, in what positions of power and privilege. Thus, when educators guided by complexity engage with students about complex ethical issues, we can commit to being inclusive, to being open to different views and consequences, and also to promoting an ethic of trust, vigilance, social justice, transparency, and inclusion when choosing how to think and act.

\section{Conclusions}

Collectively, our experiences support complexity pedagogy as one way to achieve transformations in higher education where teachers and learners are comfortable and skilled with embracing difference, creativity, and authentic relating and learning in collectives or networked spaces. We do not all agree on some aspects of the pedagogy and the Daagu platform, but at this point in time we are working together to see what possibilities might come about that support student engagement, creativity, and critical exploration and learning.

\section{ACKNOWLEDGEMENTS}

Funding for the creation of the e-Learning platform Daagu was received from: the Academic Innovation Fund at York University and the Ontario Centres of Excellence. 


\section{CONFlicts of InTERest Disclosure}

Two of the authors, Gail J. Mitchell and Nadine Cross were members of the team that created the e-learning platform. It is possible that the platform will move forward on a com- mercialization track. If the platform developed commercial value, these two authors and the sponsoring University may benefit financially.

\section{REFERENCES}

[1] Davis B, Sumara D, Luce-Kapler R. Engaging minds. Cultures of education and practices of teaching (3rd ed.). New York, NY: Routledge; 2015.

[2] Wilson-Doenges G, Gurung RAR. Benchmarks for scholarly investigations of teaching and learning. Aust J Psych. 2013; 65: 63-70. http://dx.doi.org/10.1111/ajpy.12011

[3] Garrison DR. Online community of inquiry review: Social, cognitive, and teaching presence issues. J Asynchr Learn Networks. 2007; 11(1): 61-72.

[4] Garrison DR. Thinking collaboratively: Learning in a community of inquiry. Routledge; 2015.

[5] Osberg D, Doll W, Trueit D. Limiting complexity. Complicity: An Intern J Complexity Ed. 2009; 6(2): iii-x.

[6] Bevis EO, Watson J. Towards a caring curriculum: A new pedagogy for nursing. New York, NY: National League for Nursing; 1989.

[7] Diekelmann N. Curriculum revolution: A theoretical and philosophical mandate for change. New York: National League for Nursing; 1988. PMid:3174420

[8] Diekelmann N. Engendering community: Learning to live together. J Nurs Educ. 2002; 42: 243-244.

[9] Diekelmann N. Student-centered pedagogies: Co-creating compelling experiences using new pedagogies. J Nurs Educ. 2004; 43: 245-247. PMid: 15230302

[10] Diekelmann N. Engaging the students and the teacher: Co-creating substantive reform with narrative pedagogy. J Nurs Educ. 2005; 44: 249-252. PMid: 16021800

[11] Diekelmann N, Schekel M. Leaving the safe harbour of competencybased and outcomes education: Re-thinking practice education. J Nurs Educ. 2004; 43: 385-388. PMid:15478689

[12] Giddens JF, Brady DP. Rescuing nursing education from content saturation: The case for a concept-based curriculum. J Nurs Educ. 2007; 46(2): 65-69.

[13] Giddens J, Brady D, Brown P, et al. A New Curriculum for a for a new era. Nurs Educ Perspect. 2008; 29(4): 200-204.

[14] Ironside PM. New pedagogies for teaching thinking: The lived experiences of students and teachers enacting narrative pedagogy. J Nurs Educ. 2003; 42: 509-516. PMid:14626389

[15] Johnston NE. Strengthening a praxis of suffering: teaching and learning practices. Nursing Science Quarterly. 2013; 26(3): 230235. PMid:23818470 http://dx.doi .org/10 .1177/089431841 3489183

[16] Qureshi R. Nair S. The role of higher education in emerging knowledge society, Global Journal on Humanites \& Social Sciences. 2015. 543-548 p. Available from: http://www. world-education-cen ter.org/index.php/pntsbs

[17] Adams C, van Manen M. Embodiment, virtual space, temporality, and interpersonal relations in online writing. College Quart. 2006; 9(4): $1-18$

[18] Abrami PC, Bernard R, Wade A, et al. A review of e-learning in Canada: A rough sketch of the evidence, gaps and promising direc- tions. Can J Learn Techno/La revue canadienne de l'apprentissage et de la technologie. 2008; 32(3).

[19] Finger G. eLearning: Exploring digital futures in the 21st century Educ Sci. 2014; 4(3): 209-212. http://dx.doi .org/10.3390/e ducsci4030209

[20] Lai A, Savage P. Learning management systems and principles of good teaching: Instructor and student perspectives. Can J Learn Techno. 2013; 39(3).

[21] Means B, Bakia M, Murphy R. Learning online. What research tells us about whether, when and how. New York, NY: Routledge Taylor \& Frances; 2014

[22] Rassmussen K, Belisario JM, Wark PA, et al. Offline e-learning for undergraduates in health professions: A systematic review of the impact on knowledge, skills, attitudes and satisfaction. J Global Health 2014; 4(1). PMid:24976964 http://dx.doi.org/10.7189/jog h. 04.010405

[23] Venkatesh V, Croteau AM, Rabah J. Perceptions of effectiveness of instructional uses of technology in higher education in an era of Web 2.0. In System Sciences (HICSS), 47th Hawaii International Conference. IEEE. January, 2014.

[24] Boling EC, Hough M, Krinsky H, et al. Cutting the distance in distance education: Perspectives on what promotes positive, online learning experiences. The Internet Higher Educa. 2012; 15(2): 118 126. http://dx.doi.org/10.1016/j. iheduc. 2011.11.006

[25] Price L, Kirkwood A. Using technology for teaching and learning in higher education: A critical review of the role of evidence in informing practice. Higher Educa Res Devel. 2014; 33(3): 549-564. http://dx.doi.org/10.1080/07294360.2013.841643

[26] Meyer KA. Quality in distance education: Focus on on-line learning. ASHE-ERIC Higher Education Report. Jossey-Bass Higher and Adult Education Series; 2014.

[27] Fenwick T. Reclaiming and re-embodying experiential learning through complexity science. Studies in Educ Adults. 2003; 35(2): 123-141.

[28] Byrne D. Thoughts on a pedagogy of complexity. Complicity: Int J Complex Educ. 2014; 11(2).

[29] Davis B, Sumara DJ. Complexity and education: Inquiries into learning, teaching, and research. Psychology Press; 2006.

[30] Davis B, Sumara DJ. Complexity as a theory of education. TCI (Transnational Curriculum Inquiry). 2009; 5(2): 33-44.

[31] Davis B, Sumara DJ. Fitting teacher education in/to/for an increasingly complex world. Complicity: Int J Complex Educ. 2012; 9: 30-40.

[32] Doll WE. A post-modern perspective on curriculum. New York, NY: Teachers College; 1993.

[33] Doll WE. Complexity and the culture of curriculum. Complicity: An Int J Complex Educ. 2012; 9(1): 10-29.

[34] Doll WE, Fleener MJ, Truit D, et al. Chaos, complexity, curriculum, and culture. A conversation. New York, NY: Peter Lang; 2008.

[35] Fenwick T. Puzzling "responsibility" in complexity and education In Proceedings of the Complexity Science and Educational Research Conference. Vancouver B.C. 2007. 
[36] Jacobson MJ, Wilensky U. Complex systems in education: Scientific and educational importance and implications for the learning sciences. J Learn Sci. 2006; 15: 11-34. http://dx.doi.org/10. $1207 /$ s15327809j1s1501_4

[37] Mason M. Complexity theory and the philosophy of education. Malden, MA: Wiley-Blackwell. 2008. 1-15 p. http://dx.doi.o rg/10.1002/9781444307351

[38] Morgan D, Adams J. Pedagogy first: Making web technologies work for soft skills development in leadership and management education. J Interact Learn Res. 2009; 20(2): 129-155.

[39] Osberg D. Redescribing "education" in complex terms. Complicity: Int J Complex Educ. 2005; 2(1): 81-83.

[40] Ricca B. Beyond teaching methods: A complexity approach. Complicity: Int J Complex Educ. 2012; 9(2): 31-51.
[41] Jonas-Simpson C, Mitchell GJ, Cross N. Emergence: Complexity pedagogy in action. Nursing Research and Practice. 2015 PMid:25838945 http://dx.doi .org/10.1155/2015/235075

[42] Romesin HM, Verden-Zöller G. The Origin of Humanness in the Biology of Love. Andrews UK Limited; 2012.

[43] Dewey J. Experience and education. New York: Simon \& Shuster; 1938.

[44] Freire P. Cultural action for freedom. Cambridge, MA, Harvard Educational Review and Centre for Study of Development and Social Change; 1970.

[45] Freire P. Pedagogy of the oppressed. New York: Continuum; 2000.

[46] Freire P. Pedagogy of freedom. Ethics, democracy, and civic courage. Lanham, Maryland: Rowman \& Littlefield; 2001

[47] Woermann M, Cilliers P. The ethics of complexity and the complexity of ethics. South African J of Philos. 2012; 31(2): 403-419. http://dx.doi.org/10.1080/02580136.2012.10751787 